\title{
Fracture modeling of carbonate reservoirs of Low Triassic Neftekumsk formation of hydrocarbon field in Petrel software
}

\author{
Mikhail Nelepov ${ }^{1}$, Ruslan Gridin ${ }^{1}$, Olesya Lutsenko ${ }^{1}$, Zinaida Sterlenko ${ }^{2}$, Yelena \\ Tumanova $^{2}$, Natalia Yeriomina $^{2}$, Katerina Chernenko ${ }^{2 *}$, Vladimir Gridin ${ }^{3}$ \\ ${ }^{1}$ NK Rosneft-NTC LLC, Krasnaya Street, 54, 350610, Krasnodar, Russia \\ ${ }^{2}$ Institute of Earth sciences, North-Caucasus federal university, Pr. Kulakova, 16/1, 355009, \\ Stavropol, Russia \\ ${ }^{3}$ NIPIneftegasgeologiya LLC, 45-Parallel Street, 2, office 8, 355011, Stavropol, Russia
}

\begin{abstract}
Construction of geologic and hydrodynamic models of carbonate reservoirs in the conditions of information lack about fracture parameters is always connected with the high degree of uncertainty. In the article the approach to the studying and the prediction of fracture of the carbonate reservoir based on the distribution and the trending of tectonic stress in the region of the researching object is presented. As illustrated by one of the field of the Eastern Caucasus the geotectonic description of the territory is listed, the fracture parameters on the indirect data were received, the zones of the increased productivity (fracturing) of reservoirs were highlighted and the modeling of fractures was held in Petrel software.
\end{abstract}

\section{Introduction}

The experience of the fractured reservoirs modeling shows that the standard models do not provide the history of fields development to the right degree. When development of such type of reservoirs, there are often observed the effects that cannot be explained on the basis of the classic filtration theory in porous medium. It is connected with the processes in the fracture network that considerably influence on the coefficients of wells operation and are the key ones when hydrocarbon operation $[1,2]$.

However, to make the qualitative modeling of the fracture network is necessary the big volume of the specified researches focused on the studying of geometry and physical properties of fractures in the productive horizon. Such researches are certainly made on the large hydrocarbon fields and on the fields that opened over recent years. For the small fields and the fields on the decline stage of development that are the hydrocarbon fields on the south of Russia such researches are considered as economically unviable. We have made an attempt to construct the fractures model based on the available geologic and field data.

\footnotetext{
* Corresponding author: kabiso@rambler.ru
} 
The investigating field is situated in the western part of the Caspian depression on the left bank of the Kuma river. This field opened in 1957 year and brought into development in 1958 year.

The productive horizon of Neftekumsk formation of Low Triassic is mostly composed of fractured and uneven vuggy limestones and dolomites also the subordinate interlayers of marls and argillites. Besides the interlayers of tuffs (vitric, very particulate right up to clays formation) are observed [3].The void space of rocks is presented by: primary and secondary pores, fractures, leached voids on them, vuggies, solution voids. Type of reservoir: fractured - vuggy (cavernous).

According to A.A. Khanin's classification the investigating reservoir on its reservoir properties is related to the fourth and fifth class (the decreased and low permeability). Reservoirs matrix is practically impermeable (permeability less than $0.001 \times 10^{-3} \mu^{2}$ ). Permeability ( $K_{\text {permeability }}$ ) conditioned on the rocks fracturing was not determined according to the core. According to the data of the hydrodynamic wells researches the permeability of carbonate reservoirs is changed within the limits $13 \times 10^{-3}-158 \times 10^{-3} \mu^{2}$, and is on average $68 \times 10^{-3} \mu^{2}$.

Small sizes of pores condition on the inefficiency of the pore space of matrix in determination of fluid storage and filtration possibilities of the carbonate reservoir. The porosity of the carbonate rocks is mainly $2-3 \%$ and only in the single instances increases up to $8-10 \%$.

The main voids forming the effective void space of rocks are fractures, vuggies and leached pores. There has been observed the development of the three fracture networks responsible for filtration rocks property: horizontal, vertical and diagonal ones. The width of fractures is $0.01-1.5 \mathrm{~mm}$. The distance between fractures is changing within the wide limits: $1-40 \mathrm{~mm}$ and more. The fracture intensity is most often 150-200 1/m having changed from 80 up to $800 \mathrm{1} / \mathrm{m}$. There has been observed the fractures: open and filled by calcite or clay material, more rarely by pyrite.

\section{Materials and methods}

The study of the fractured reservoirs and the construction of high-quality geologic models by Schlumberger are realized in accordance with the perfected common order and tasks sequence [4]. When fracture modeling, one chooses an algorithm: either the algorithm of continuous fracture network modeling $(\mathrm{CFN})$ or the algorithm of discrete fracture network modeling, that is the distribution of the fractures as objects (DFN). Each of them has its advantages and disadvantages. In the modeling process a module Facture network modeling is applied; it includes the full set of tools to construct a fracture model and its transformation to a model of double porosity/double permeability. The upscaling is applied after the fracture network construction.

The method allows predicting the full set of fracture parameters and applying them later when rescaling of the models of fractured porosity, permeability and sigma-factor for hydrodynamic modeling.

The necessary information to construct DFN is the knowledge about lithologic characteristics of the investigating object, sedimentation conditions, and degree of diagenetic alterations and it is of the first importance - tectonic movements in the region and within the limits of the modeling field. Information about tectonics of the investigating objects allows gaining the insight about the distribution and the trending of the tectonic stress that influences straightly on the process of fracture formation [4].

To make a qualitative modeling of the fractured reservoirs is important:

- information obtainable from the microimagers or from the core about fractures geometry (strike and plunge); 
- dynamic data according to the hydrodynamic well tests or the history of production (for calibrating of fracture network);

- laboratory geochemical core researches;

- results of 3D seismic survey (to determine the fracture intensity in the interwell space);

- any data that can be direct or indirect features of the fractured intervals or can describe fractures in a reservoir including data on drilling mud losses.

When construction of DFN, the important parameters that influence on a character of the fracture network are fracture intensity and its space distribution, geometry (form, length-height ratio, character of distribution of fracture length, range of values and especially important parameter - maximal length), space orientation, opening that conditions on fracture permeability.

\section{Evaluation of initial data of the hydrocarbon field with the aim of fracture modeling}

The modeling experience of fractures in Russia and abroad $[5,6,7,8]$ shows that a modeler does not often have the full set of parameters describing the fractures. The most significant parameters for fracture modeling are the next: trending, opening and length (extent) of separate fractures also distribution of fracture density in the space.

There had not been the special researches of fracturing by the methods of the seismic survey or with the help of the FMI device (azimuthal electric microimager) on the investigating field. The core researches also had not been oriented in the cardinal directions, but the separate samples caught in 60 's -70 's of the past century are unable to image the truthful overview of fracturing. Despite this fact one can receive fracturing parameters on the indirect data - on the basis of tectonic researches, aerospace researches and analysis of wells performance of the productive horizon.

The development of the hydrocarbon fields of the East Stavropolie has been carried out many decades. It allowed accumulating the extensive material as about the geologic structure of the region as about the parameters of the fields development. In southern Russia when planning of the development system and the carrying out of geologic and technical actions of oil-and-gas fields, the importance of fracturing influence on the reservoir properties of rocks is often underestimated [1]. At the same time the geomechanical characteristics of the reservoirs nearby the disjunctive dislocations has the significant differences from unbroken areas and in the first place it is connected with the system of micro-, mini- and macro- fractures accompanying by the discharge zones of tectonic stresses $[2,4]$.

\section{Geotectonic characteristics of the territory}

Tectonically the concerned region strains the action of the two differently-directed stresses: one from the side of uplifting Alpine-Caucasus fold system in the region of the Greater Caucasus Mountain Range and another - in perpendicular trending from the side of uplifting Stavropol dome (figure 1). Discharge of stresses of the earth crust happens through the deep faults creating the system of basement blocks. These faults are discovered by the set of geophysical surveys and by drilling of the exploration wells. According to the data of aerospace researches the blocks that were marked on the deep faults are broken into more small ones that have the subordinate value and the inherited character in the trendings of the secondary breaks [9]. More small lines of breaks are marked straightforwardly inside the fields; these lines are of N-S and E-W trendings coinciding with the zones of the 
maximal cumulative oil withdrawals. It is true to form that their trendings are similar to the trending of the deep faults. For the first time these linear zones were discovered in Aptian age of the investigating field (figure 2) [1].

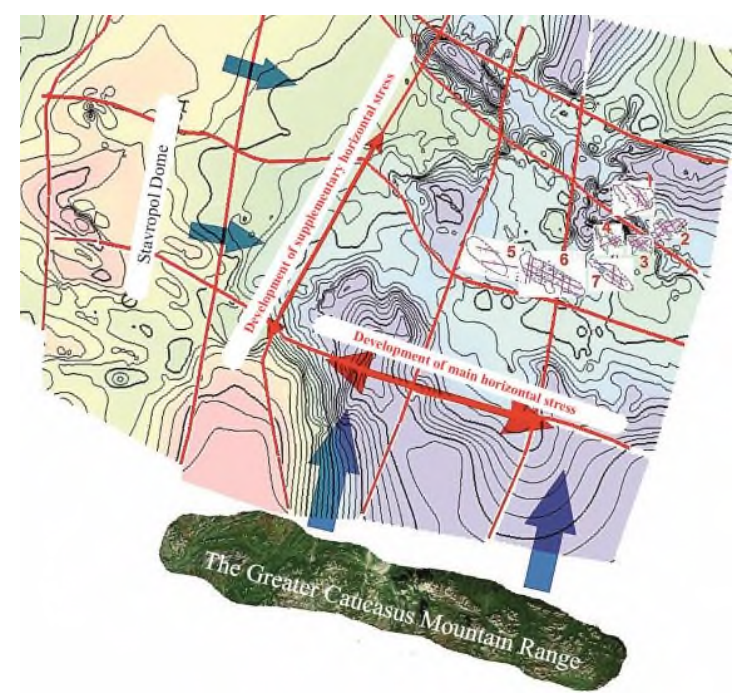

Legends: 1,2,3 - number of hydrocarbon fields
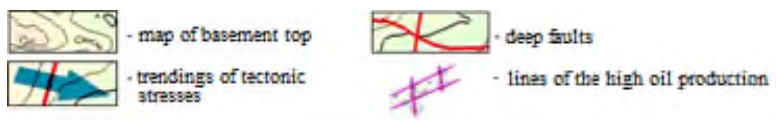

Fig. 1. Geotectonic characteristics of the territory.

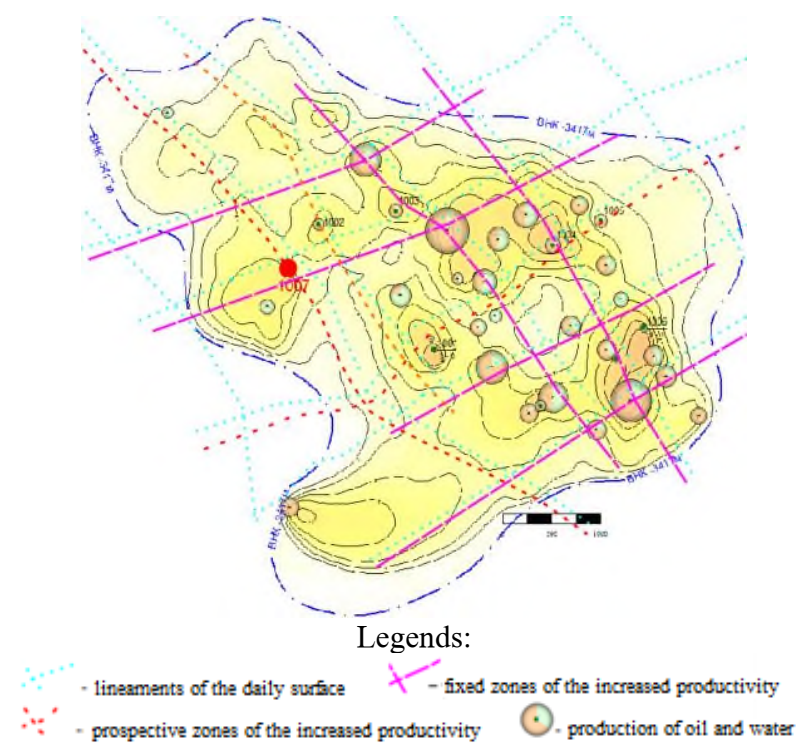

Fig. 2. Map of layout of the zones with the increased productivity of the Aptian horizon on the field.

The analysis of the cumulative production on the wells of the field showed that wells with the high cumulative oil production are situated along E-W and N-S linear zones; these zones do not attach to the plicate structural framework and are not connected with the development system. Subsequently such linear zones have been discovered on the other 
hydrocarbon fields of the Stavropol region as in the carbonate an in the terrigenous horizons. The explanation of these zones is in the geodynamic processes taking place in the earth's crust: the sections of local extension and compression which are characterized by the different permeability appear in the places of intersection of the differently-directed movements of basement blocks: fractures are more open on the extension sections that leads to their increased permeability and correspondently more high rates of hydrocarbon.

Having made the analysis on the several fields it was noticed that the trendings of the zones with the increased oil production are similar to the tending of deep faults. This pattern is viewed on the whole cross-section; having appeared in a greater or lesser degree depending on wells quantity that have taken part in the horizon development [10]. Taking into consideration the genesis of these zones, it becomes clear the close correlation of the zones of the increased cumulative oil production on wells with the lineaments of the daily surface.

\section{Definition of the increased productivity (fracturing) zones of reservoirs of Neftekumsk formation (Low Triassic)}

The first object of development that marked out on the initial stage has been developing since 1975 by the wells 43 and 151 . The maximal oil production from the accumulation was achieved in $2017-44$ thousand tons. The cumulative production map of this accumulation is shown in figure 3 .

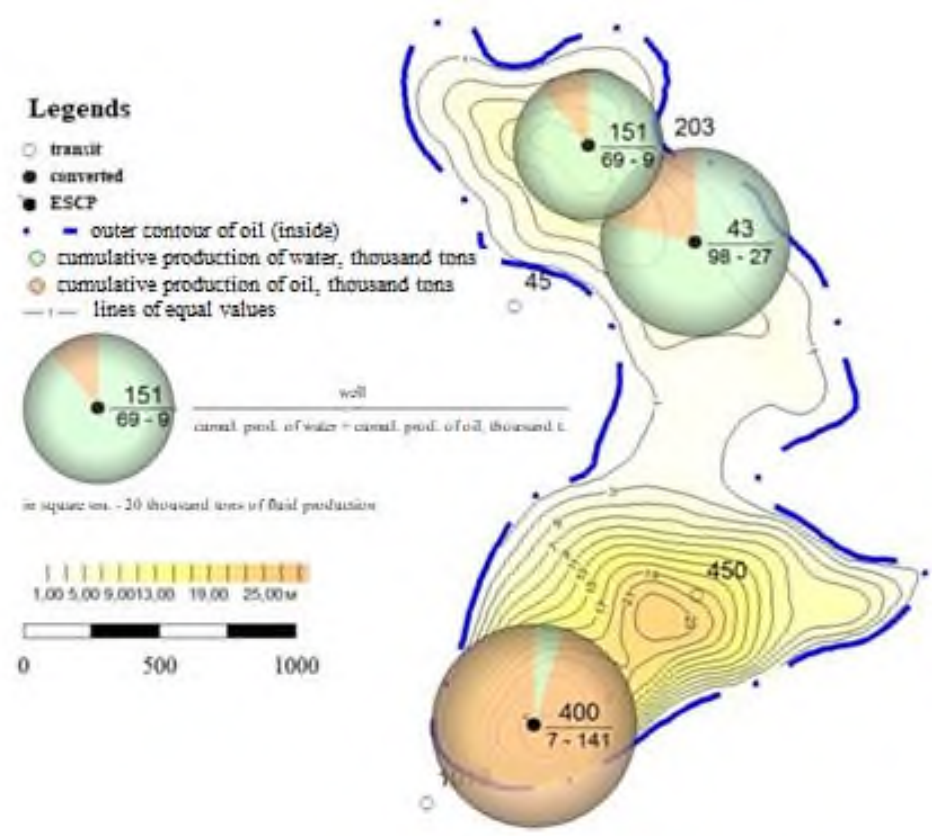

Fig. 3. Cumulative production map of $\mathrm{T}_{1} \mathrm{O}$ object, Neftekumsk formation as on $01 / 01 / 2019$ and location of the zones of the increased productivity of horizon.

There has been proved in many articles that the lineaments reflect the trendings of the disjunctive dislocations to high precision and consequently the fracturing of rocks. It is shown in figure 4 that the trending of the daily surface lineaments of the filed coincides with the zones of the increased productivity on the cumulative oil production in two main trendings. In many instances the areas of the productive horizons are situated under the 
lineaments, but in the junctions of lineaments intersection they possess the enhanced reservoir properties. Thus we can get an idea about the space distribution of fracturing.

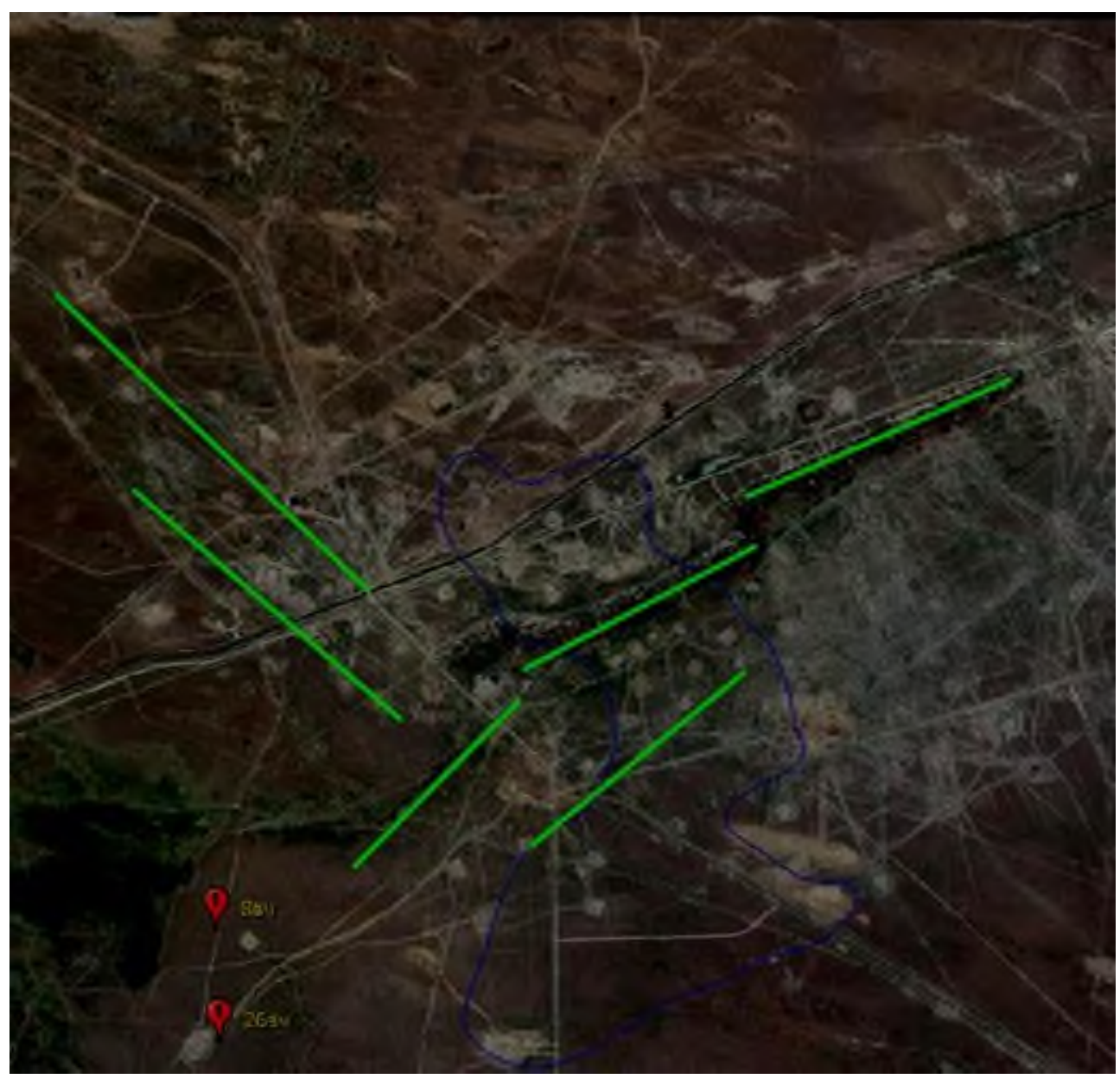

Fig. 4. Chart of lineaments of the field.

\section{Fracture modeling of Low Triassic Neftekumsk formation in the software Petrel}

To make modeling we had built the trend map of the fracture density. At the first stage we conditionally took the fracture density that is equal 0.9 at the center of zone of the increased porosity, but at the periphery -0.5 (figure 5).

The next admissions were taken for the parameters of the single fractures: the modeling fractures have been taken as open with maximal length of the single fracture that is equal $1 / 10$ of the average distance between wells. This value for Neftekumsk formation is $50 \mathrm{~m}$. 


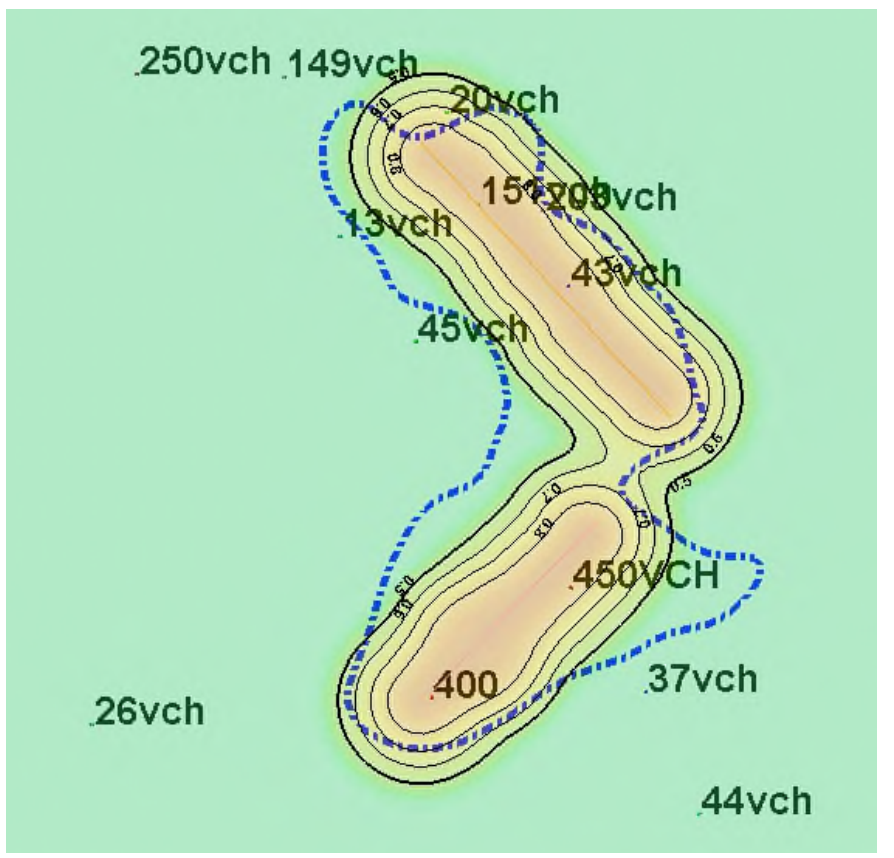

Fig. 5. Trend map of fracture density.

Fracture modeling was made in the process of Fracture network modeling. At the first stage the fracturing network was created. We made two variants: with the equal fracture distribution (figure $6 \mathrm{~A}$ ) and with the application of the trend map of the fracture density (figure 6 B).

In the fold of the process for the fracture network creation the cube of lithology was chosen, in which the fracture network is produced as in the reservoir as in the non-reservoir. The stochastic algorithm was chosen for the fracture distribution. The fracture distribution was made in correspondence with the trend map of fracturing that was constructed by us. Before construction the template Matrix-fracture coupling was set for this map.

Inasmuch there is as horizontal as vertical fracturing in the modeling deposits; the ratio of length of horizon fractures to vertical ones (i.e. elongation ratio) was taken 1:2 by us according to the photos of the core samples. The main orientation of the fractures was taken on the lineaments $43^{\circ}$. The normal distribution for the permeability was taken. The obtained fracture network was shown in figure 6 . 


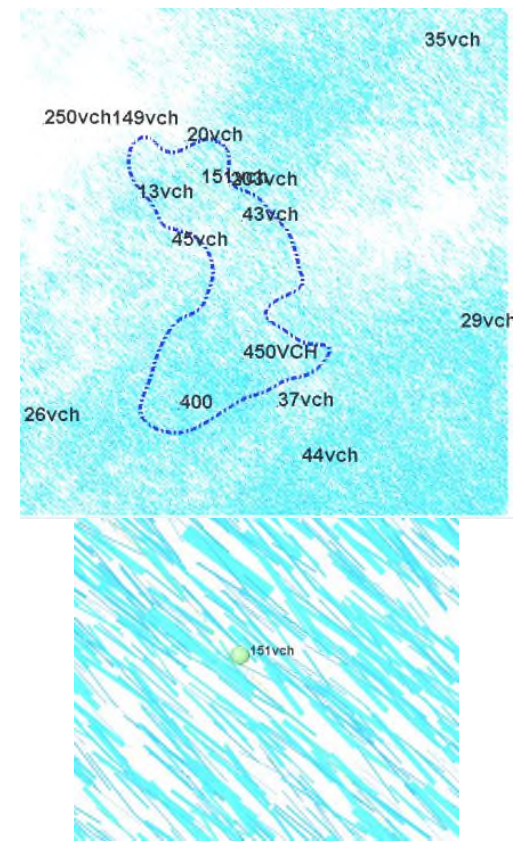

A - equal fracture distribution

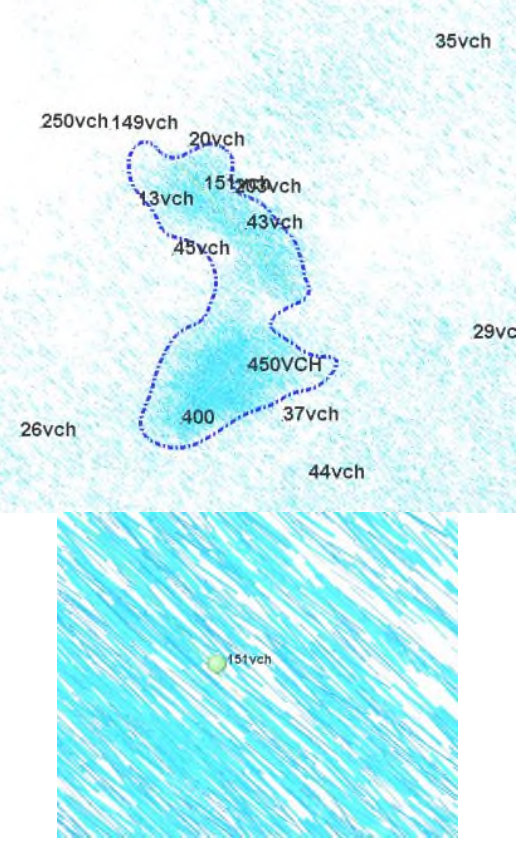

B - fracture distribution with the application of trend map

Fig. 6. Fracture network of Low Triassic Neftekumsk formation.

The upscaling was applied with the help of Od's method after the construction of the fracture network; the next cubes are received at the output: the permeability cube on three directions $(\mathrm{x} ; \mathrm{y} ; \mathrm{z})$, the cube of the fractured porosity (usually with porosity less than 0.01 ), the cube with the sigma-factor in every grid block, this cube conditions on the interaction between the porosity/permeability cubes.

The final cube of the fractured porosity of the horizon is shown in figure 7 .

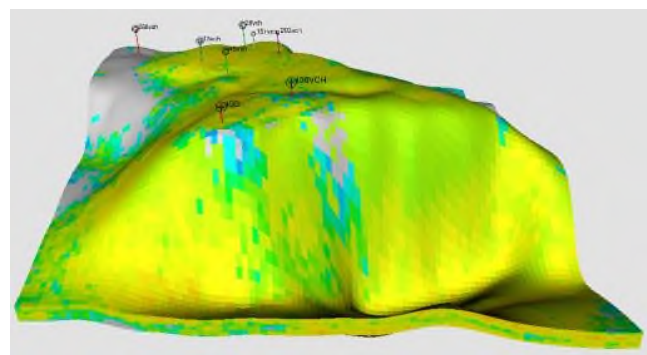

A - equal fracture distribution

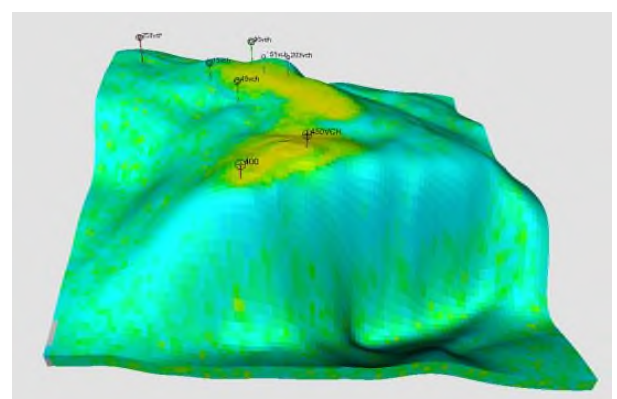

B - fracture distribution with the application of trend map

Fig. 7. Final cube of fractured porosity of the horizon.

\section{Conclusion}

As illustrated by Low Triassic Neftekumsk formation of one of the hydrocarbon fields of Velichaevsko-Maksimokumskaya structural zone there were shown the possibilities and difficulties appearing at fracturing construction in the software Petrel for the fields of the Eastern Stavropolie. We have shown that having possessed even the insignificant portion of 
knowledge about fracturing of the reservoirs, the application of the simplified algorithms of the construction of the double medium model can allow reproducing more precisely the history of objects development and giving more high-quality prediction of indexes for prospects.

\section{Acknowledgements}

The reported study was funded by RFBR, project number 20-35-90028.

\section{References}

1. M.V. Nelepov, Neftyanoe khozyaystvo - Oil industry 9(1104), 96-97 (2015) eLIBRARY ID: 24227607

2. S.V. Nelepov, P.V. Ilchenko, M.V. Nelepov, Gas industry 3, 19-22 (2015) eLIBRARY ID: 23022254

3. I.A. Burlakov, M.S. Plotnikov, A.I. Rybakova, Papers of SevKavNIPIneft XXV, 97103 (1976)

4. V. Blekhman, M. Krenov, L. SHmarian, I. Priezzhev, Methodology of modeling of fractured terrigenous reservoirs in the Western Siberia, Science and technologies. Exploration and development (Schlumberger company, 2009) eLIBRARY ID: 9908095

5. P.P. Azarov, Construction of double porosity model of carbonate reservoirs in the conditions of data lack of special methods of wells geophysical surveys, IX Scientificpractical conference "Mathematic modeling and computer technologies in fields development» (Moscow, 2016)

6. Z.O. Opafuso, Journal of engineering and applied sciences 2(11), 1651-1660 (2007) DOI https://medwelljournals.com/abstract/?doi=jeasci.2007.1651.1660

7. A.A. El Khadragy, E.A. Eysa, A. Hashim, A.Abd El Kader, Journal of African earth sciences 132, 99-108 (2017) DOI https://doi.org/10.1016/j.jafrearsci.2017.04.032

8. M. Alizadeha, Z. Movaheda, R. Junina, R. Mohsina, M. Alizadehb, M. Alizadehc, Fracture modeling in oil and gas reservoirs using image logs data and Petrel software, Mechanical Engineering Department, Tarbiat Modares University (Iran) 75(11), 25-32 (2015) DOI: 10.11113/jt.v75.5295

9. N.I. Korchuganova, A.K. Korsakov, Distant methods of geologic mapping (Book house University, Moscow, 2009)

10. M.V. Nelepov, D.V. Tomashev, A.A. Paporotnaya, Neftepromislovoe delo 7(607), 2833 (2019) DOI: 10.30713/0207-2351-2019-7(607)-28-32 